\title{
Histopathological Changes and Harmful Effects of Garamycin (60) Mg by Intramuscular Injection in Experimental White Rats
}

\author{
Mohammed A. Hassan, Lamya M. Shaker and Aliaa A. Hammouda \\ Biology Science Department, College of Education for Girls / Thi-Qar University, Republic of Iraq. \\ "Corresponding author. Email: mohammedn10@utq.edu.iq
}

\begin{abstract}
This study has shown the effects of gentamicin sulfate injection $(60 \mathrm{mg} / \mathrm{kg} / \mathrm{b}$.w.) in thigh muscle for two months twice daily (morning and evening) on the histological structure of the kidneys, liver and cardiac muscle of rats. Vacuolation, dilatated cortical tubules and degeneration, necrosis of proximal convoluted tubules were seen in the treated group. Congestion, cardiac muscle vacuolation as well as hepatocytes degeneration and sinusoids congestion with obvious bile duct proliferation were also seen.

Through our studies showed clinical findings such as anorexia and subsequent emaciation and certain animals were presumably killed in the treatment group due to gentamicin caused renal failure.
\end{abstract}

Keywords: Garamycin, Hepatopathy, Nephropathy, clinical findings.

\section{INTRODUCTION}

Gentamicin, an aminoglycoside antibiotic, consists of an aminocyclitol 2-deoxystroptamine molecule and additional amino sugars, a combination of basic, water-soluble chemicals. $\mathrm{Clf}, \mathrm{Cj}$ and $\mathrm{Cla}$ are defined as the three principal active elements however gentamicins $\mathrm{A}, \mathrm{B}$ and $\mathrm{X}$ are also available as minor active components. The gentamicin $\mathrm{C}$ complex is generally manufactured as the colorless, odorless and water-soluble sulfate salt, a white-to-buff powder. After $\mathrm{pH}$ adjustment, the ion exchange technique for the fermentation broth and filtering is commonly used to commercially separate and purify gentamycin [1].

The treatment of many infectious diseases is frequently utilized by Gentamicin in human being and Vet. medicine. It is used to treat a number of sensitive bacterial infections (e.g., swine-colic and peritonitis; urogenital tract problems, trachea and lungs disorder) in swine, poultry and bovine diseases [2]. Various gentamicin formulations for the treatment of animals generating food have been produced. These are part of other antibiotics, including penicillin G, ampicillin and cloxacillin. For the administration via injection, infusion, or therapy or in the formulation of an addition to drinking water the formulated products generally include $4-80 \mathrm{mg} / \mathrm{ml}$ of gentamicin [3]. It is swept or injected and results in elevated renal cortex and inner ears. Nephrotoxicity and ototoxicity were the frequent clinical results of gentamicin toxicity [4]. Most of the injected aminoglycoside is eliminated without metabolization into the urine. The rest of the administered dosage nevertheless accumulates in the renal cortex selectively and abundantly. Aminoglycoside is continuously absorbing in renal, proximal tubular cells there for long periods of time, resulting in severe damage, including structural changes and plasma membrane, mitochondria and lysosomal function. [5]. Garamycin is absorbed into renal proximal tubular cells throughout the border brush. Based on the aminoglycosides binding to the brush-border membrane, receptor-mediated endocytosis has thus far been reported. The glomerular physiology of aminoglycosides has been directly disrupted, which decreases the SNGFR through both a decrease in $\mathrm{Kf}$ and the glomerular arterial output SNGFR [6]. Vascular, glomerular and tubular targets have been shown to have drug-induced 
nephrotoxicity as a consequence of the interference between the normal and functional structures of the cell (mitochondria, membrane integrity...), cellular, and luminal blockage tubular swelling [7] (through osmotic effects). Very few histopathological investigations have been published in rat histopathology literature. The objective of this work

is to explore the toxic-pathological events of garamycin with lab-rats to prevent adverse effects on people and to pave the way for further research into garamycin toxicity and related antibiotics of aminoglycosides that can benefit people or another Vet. uses.

\section{METHODOLOGY}

Both sexes $(250 \pm 10) \mathrm{g}$ bodily weight and six weeks old were tested. They were gathered from science and held for a time of adjustment ( 2 weeks). Rates in the same composite animal home were confined in wire mesh cages under ambient light. It was separated into 2 groups of eight rats each (4 male and 4 female). Group I animals have been maintained without therapy (untreated control). For sixty days, the garamycin ( Gentafar, 10 percent farvet, the Netherlands) was injected into Thigh Muscle/I.M. twice a day (morning and evening), namely $2^{\text {nd }}$ or treated group. Clinical indicators were observed during the trial period. Immediately following euthanasia, kidneys, liver, bile, and heart were separated and set to room temperature for 24 hours by $10 \%$ formaldehyde.

The specimens were next dehydrated before paraffin was included by a graduated range of ethanol and xylene from the buffered formalin. The samples were subsequently incorporated into paraffin, divided into 5 microns by rotating microtomes and filled with haematoxyline eosin as reported by [8]. The tobacco was then checked for histopathological alterations caused by gentamicin under the light microscope (Olympus) to be detected and described.

\section{RESULTS}

These lesions range from organ to organ but were evident and important in the kidney and others organ such as liver, bile ducts and heart displayed diverse lesions. In addition, the results of our experiment indicated different histological injuries.

Control rat kidney slides exhibited normal histological glomerular structures, and cortical and medullary renal tubular structures (Fig.1). Hepatocytes, bile ducts and central vein had normal limit indicated normal and control group liver sections (Fig.2).

The histo-pathological alterations in kidneys and sections of urinary tubules were diverse in animals treated with $(60) \mathrm{mg} / \mathrm{km}$. garamycin for (60) days, and the changes vary from the vacuolation of the renal cells to cortical tubules dilations (Figs 3,4,5,6). The necrosis of proximally convoluted tubules also resembled a tragic renal wound (Fig 7,8,9). In the epithelial cells of the renal tubes in the subcapsular kidney zone, degeneration and necrosis were also reported (Figs 10,11). Vacuolation and necrosis of the proximal convoluted tubules have been reported in figures $(12,13,14)$. Dilatation in medullary tubules with vascular lumen, affected by hemolytic blood, were shown by pathogenic findings in (Figs 15,16). Degeneration and congestion of myocardial muscle cells were seen clearly in (Fig 17).

On the other side, the sinusoidal space and hepatic central vein in the peri acinar zone were congested while a minimal vacuolation of hepatocytes were seen in the same zone, (Fig 18). On the other hand, (Figs 19,20) showed proliferation of bile duct. Anorexia and eventual emaciation and mortality were found in certain experimental animals, possibly in the kidneys, liver, bile duct and heart as described above.

\section{DISCUSSIONS}

The majority of the injected aminoglycoside is eliminated without metabolism into the urine. The remaining administered dosage, however, accumulates in the renal cortex selectively and abundantly. The renal proximal tubular cells remain in the aminoglycoside for a long length of time leading to kidney damage such as structural alterations and plasma membrane functional impairment, mitochondria, and lysosoma (MingeotLeclerq and Tulkens 1999). The process by which aminoglycosides are absorbed into the proximal cells of the renal tubular membrane across the border membrane was therefore very interested. Based on the aminoglycosides binding to the brush-border membrane, receptor-medicated endocytosis has been shown to date. Aminoglycosides may directly alter glomerular physiology and reduce SNGFR by lowering both KF and GAF (glomerulo-arteriolar outflow) (Baylis et al., 1977).

Results of study by Perazellla (2003) demonstrated that the intratubal obstruction (crystal deposition) causes kidney damage, causes cellular swelling and occult tumors, both vascular, glomerular and tubular, through mechanisms which disturb normal cell structures and 
functions (mitochondria, membrane integrity, etc) (through osmotic effects). These effects were observed (Sousa et al., 2009). Many researchers were aware of the prevalence of renal impairment after the use of aminoglycoside (Garetz and Schacht, 1996; Baliga et al., 1997 and Abdel Naim et al., 1999). Garamycin is a broad-spectrum aminoglycoside antibiotic used as antibacterial agent (-ve and +ve) (Taha, 1993). Our study has shown that aminoglycosides can induce animal organ damage such as the kidney, liver, bile duct and heart if improperly given. All amino-glycosides used in particular gentamicin have created much more nitrogen waste (urea, uric acid and creatinine), as indicated in the blood (Heibashy and Abdel Moneim, 1999; Heibashy et al., 2009) who reported that Garamycin intake in rats produced renal function impairment by releasing oxygen free radical (oxidative stress). Acute renal failure is marked by disturbances that have resulted in increased blood urea, creatinine and uric acid concentrations in rats being treated with gentamicin $60 \mathrm{mg} / \mathrm{kg}$ B.w. and $80 \mathrm{mg} / \mathrm{kg} \mathrm{B.w.} \mathrm{According}$ to our experiment results; gentamicin produced severe nephrotoxicity and this finding reinforce those of (Ali et al., 2003; Goto, 2004 and Heibashy et al., 2009) who found that gentamicin produced nephrotoxicity. And similar results, have been reported by others (Kavutcu et al., 1996; Kumar et al., 1999 and Chilwant and Muglikar, 2012) who reported that protectivlly 30 days of administered honey and 15 days simultaneously with gentamicin (GR-IV) gave nephrotoxicity prevention. Furthermore, honey administration for 15 days, with gentamicin, was not protected against nephrotoxicity for a short period of time. It appears that long-term prophylactic honey treatment protects against gentamicin-induced nephrotoxicity. Many findings show aminoglycoside antibiotics are nephrotoxic and an oxidative stress is the fundamental mechanism for explaining the pathophysiology. Some free radical scavengers offer significant functional and histological toxicity protection. This implies that gentamicin may have a significant effect on free radical metabolism in the renal tissue. Studies have shown that in renal tissue that has been exposed to gentamicin, enzyme free radical defense has been substantially disrupted. Free radical scavenging is the protection way of antioxidant from nephrotoxicity caused by oxidative stress imbalance, also, our findings reinforce those of (Bennett et al., 1979 and Herscovici et al., 1988) who found that urinary tract disorder with animal models revealed that garamycin or tobramycin was once daily far less harmful than more common.t (i.e., twice or three times daily) dosages or continuous infusion.
In our investigations, other microscopic findings show prominent changes in the kidney (cortical tubules, medullary tubules, and proximally convoluted tubules), such as expanded renal dilations, degenerations, and necroses, which can be caused by cytotoxic effects of gentamicin and tubular cell necrosis. Similar to the results of tubular necrosis, different researchers in different species including newborn puppies have shown a consistent finding of gentamicin toxicity (Cowan et al., 1980), rats (McMartin et al., 1982), horses (Godber et al., 1985) and avian species (Khan et al., 2008; Saleemi et al., 2009; Islam et al., 2011), and these our findings agreed with other authors who reported that rats treated with garamycin show intense granular degenerated, tubular epithelial damage with $>50$ per cent of renal cortex and garamycin -treated rats in midscale's showed: tubular necrosis, degeneration, proximal tubular cell regenerations, cell interstitial infiltrations, and hyaline cast formation in tubular lumen. ( Gobe et al., 1987 and Yoshiyama et al., 1992), more than half of proximal tubules showing desquamation of necrosis but involved tubules easily found, complete or almost complete tubular necrosis (Padmini and Kumar, 2012) and the nephrotoxicity of aminoglycosides is characterized by the reduction in glomerular filtration and modification in the intralomerular dynamic of tubular necrosis, basal disorder, mesangial cell contraction, proliferation, and apoptosis. (Bennett, 1986).

Many pathological changes in the liver of rats have shown significant vacuolation, limited hepatocyte destruction and central venous congestion with the impact of gentmicin. This is justified since the hepatocytes for this medicine are more susceptible to the harmful effects. During liver metabolism, hepatocytes also come into touch with hazardous substances. These findings reinforce those of the experimental and clinical gentamicins toxicity reported in commercial White Leghorn birds (Khan et al., 2008; Islam et al., 2011 and Javed et al., 2013) that produce high mortality and toxic-pathological changes in kidneying and liver, such as hepatocyte vacuolar. This finding has been agreed with (Javed et al. 2013), showing $30 \mathrm{mg} / \mathrm{kg}$ of garamycin pathogenic liver modification consisting in increased gravity and frequency of fatty alterations and rising dose level, serious congestion of the hepatocyte, and changes of hepatocytes, once genetically modified pectoral bird muscles have a weight of 40,50 and $70 \mathrm{mg} / \mathrm{kg}$. As serum protein synthesis in the liver occurs, seriously damaged hepatic synthesis might also diminish. Bird liver supplied $30 \mathrm{mg}$ and above the gentamicin levels indicated an adverse impact and anorexia in the birds 
(Benjamin, 1978; Muhammad et al., 2012). This combination of lesions showed that anorexia and subsequent emaciation of rats might be mainly caused by kidney and liver damage followed by gentamicin treatment.

The current study also shown that vacuolations and congestion of cardiac muscle cells produced by gentamicin treatment rats. This is similar with earlier research (Javed et al., 2013), where the observed emaciation was followed with enlarged kidney, liver, and hematizedness on diverse organ, including heart, observed in different groups that received gentamicin.

\section{CONCLUSION}

In conclusion, this survey shows the harmful effects on the kidney, liver, and heart of gentamicin while this medicine is being used. Therefore, further study must be carried out on various bodies in the body to emphasize its impacts on these bodies.

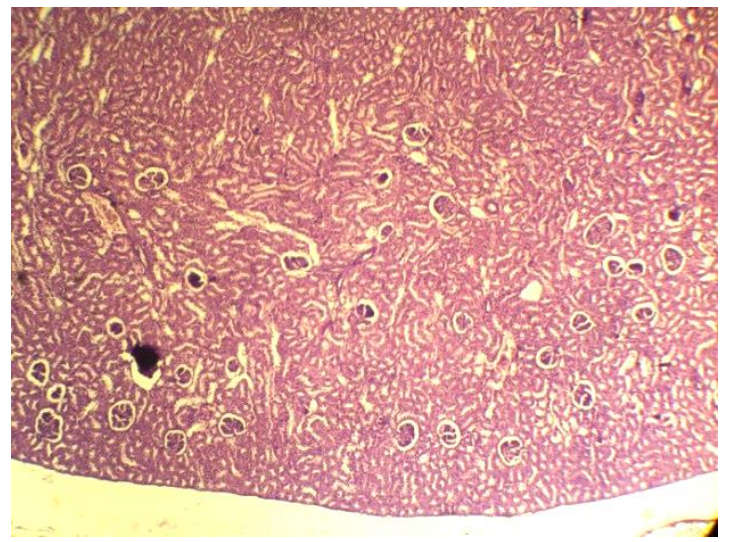

Figure 1 Kidney; control, within normal limits. (H \& E, $4 \mathrm{x})$.

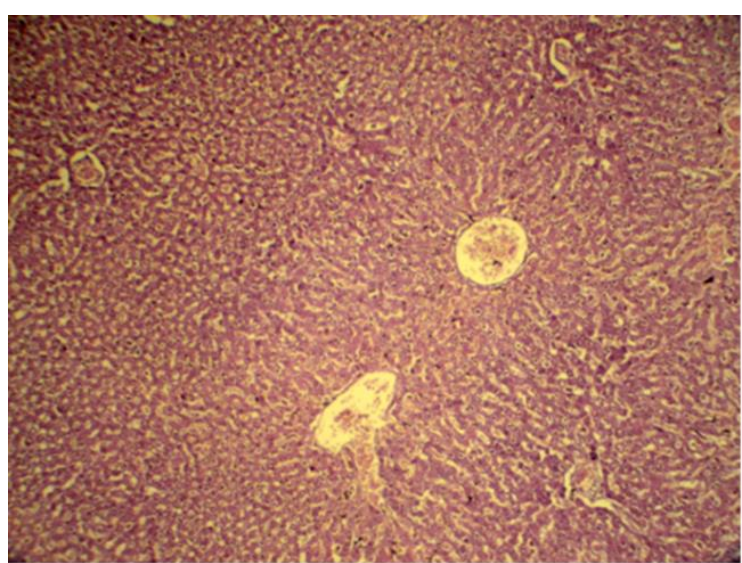

Fig 2 Liver; control, within normal structure. (H \& E, $4 \mathrm{x})$.

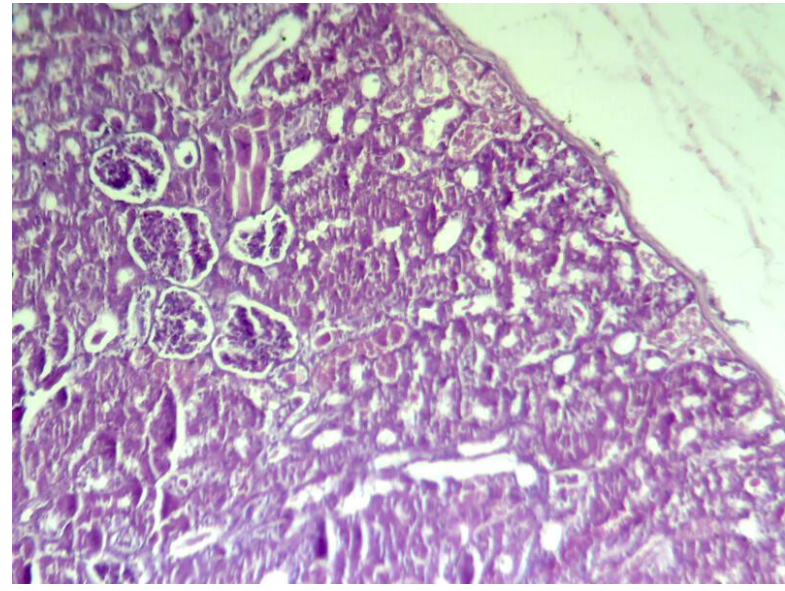

Fig 3 Kidney; dilatation and vacuolation of cortical tubules $\left(\mathrm{H} \& \mathrm{E}, 10_{\mathrm{X}}\right)$.

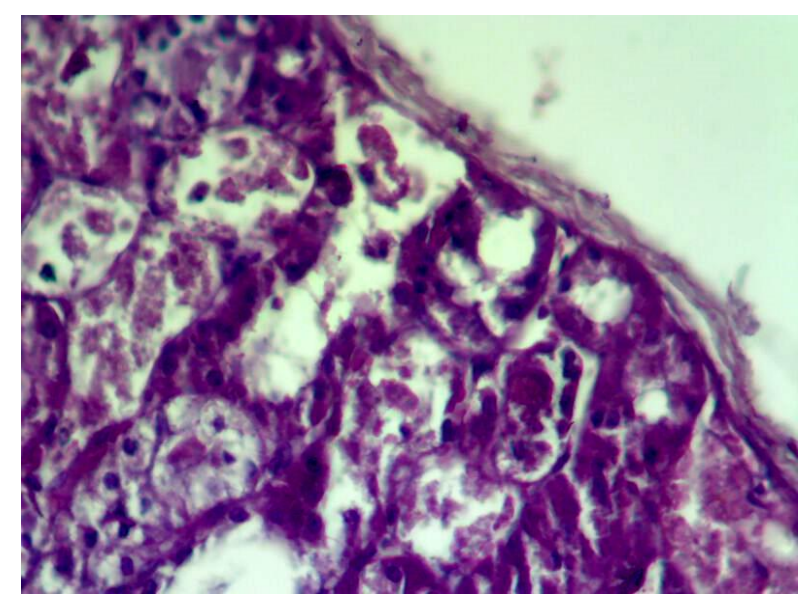

Fig 4 Kidney; dilatation and vacuolation of cortical tubules $\left(\mathrm{H} \& \mathrm{E}, 40_{\mathrm{X}}\right)$.

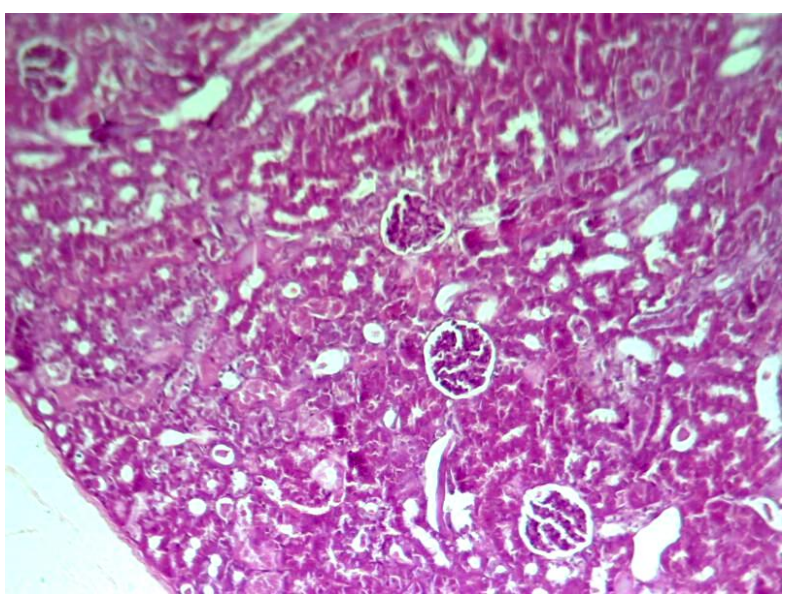

Fig 5 Kidney; dilatation of cortical tubules (H \& E, $10 \mathrm{X})$. 


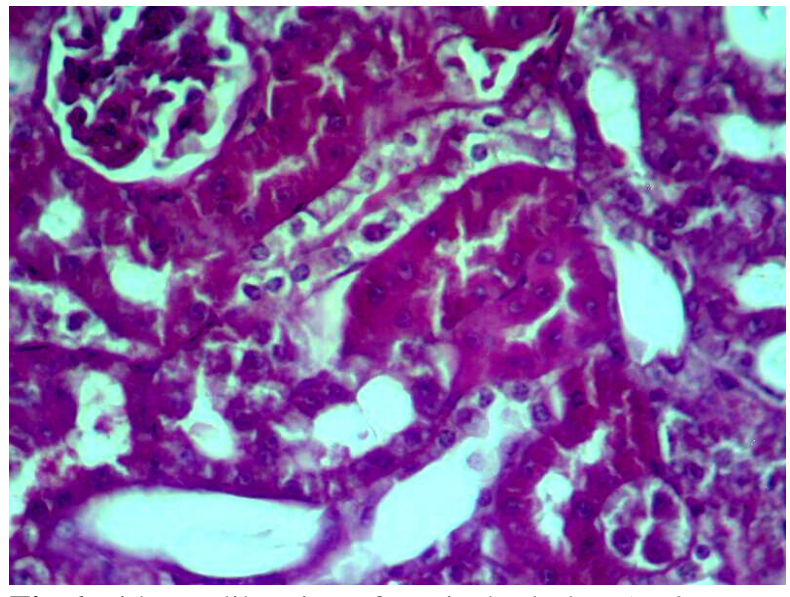

Fig 6 Kidney; dilatation of cortical tubules. (H \& E,

$40 \mathrm{x})$.

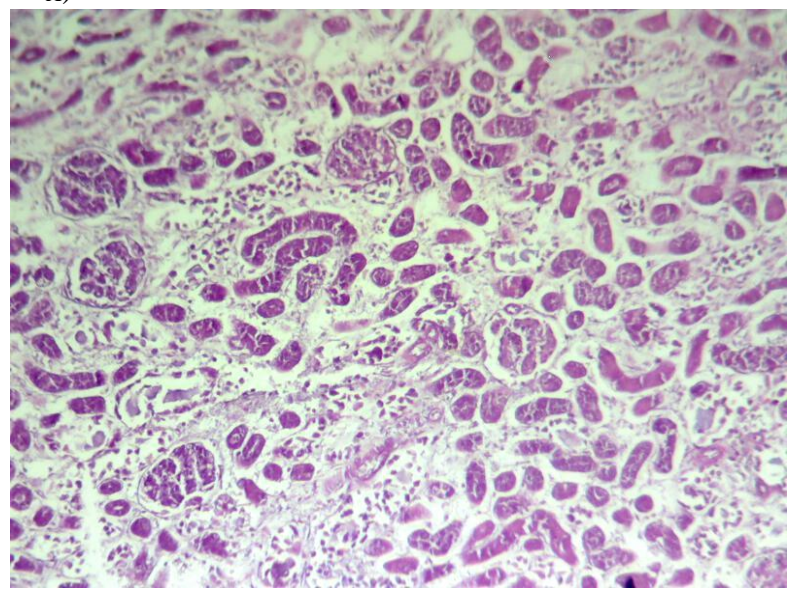

Fig 7 Kidney; necrosis of proximal convoluted tubules $\left(\mathrm{H} \& \mathrm{E}, 4_{\mathrm{X}}\right)$.

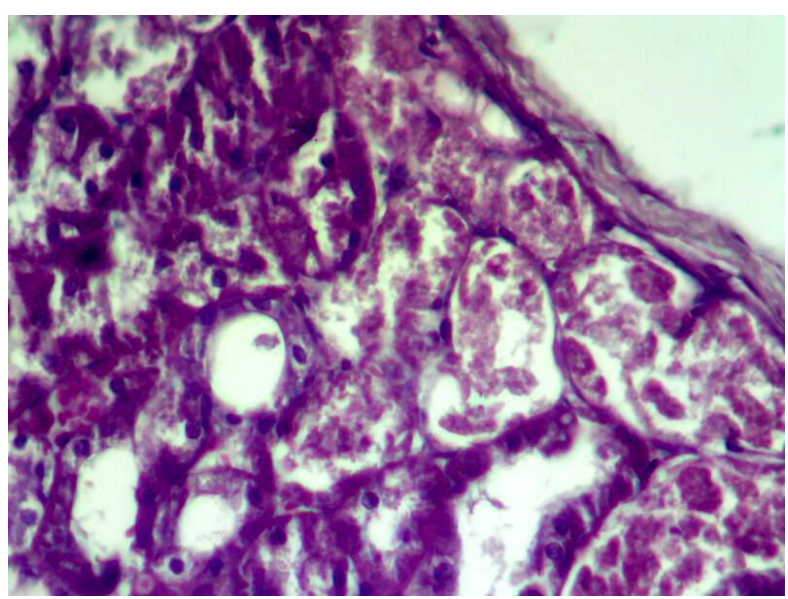

Fig 8 Kidney; necrosis of proximal convoluted tubules $\left(\mathrm{H} \& \mathrm{E}, 10_{\mathrm{X}}\right)$.

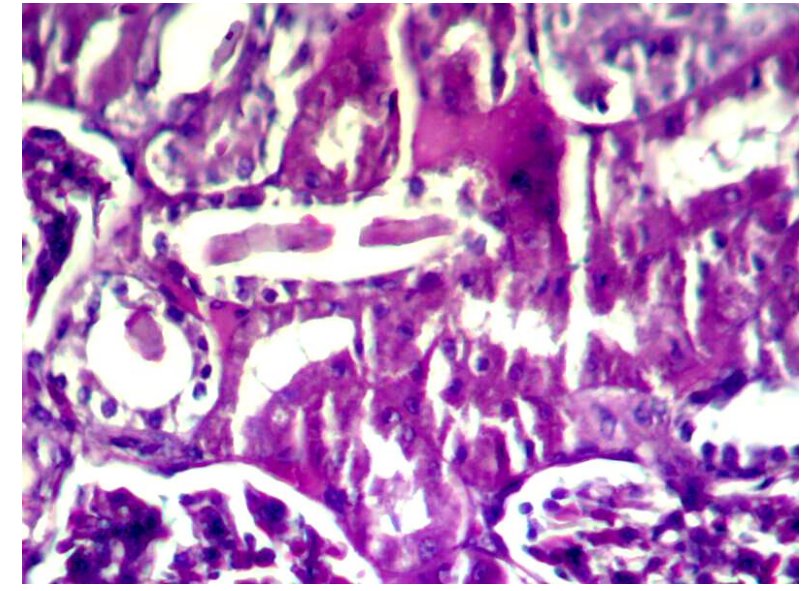

Fig 9 Kidney; necrosis of proximal convoluted tubules $(\mathrm{H} \& \mathrm{E}, 40 \mathrm{x})$.

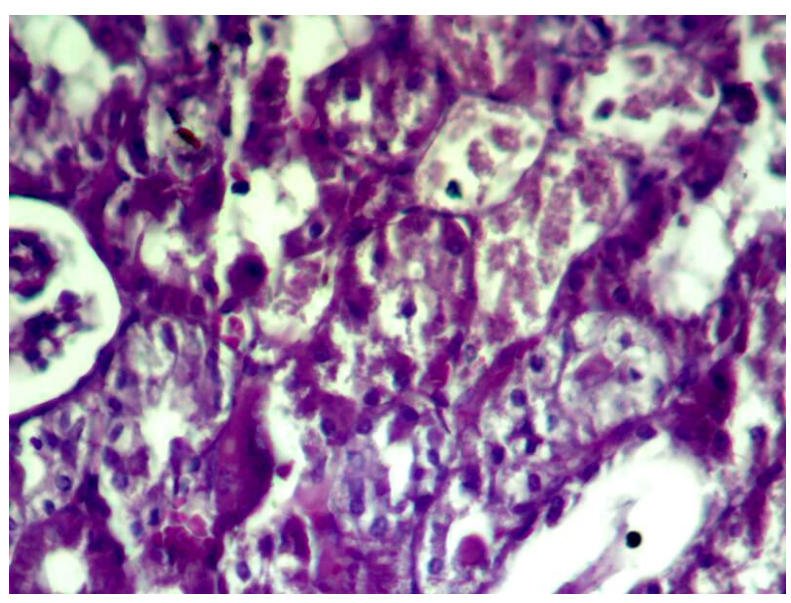

Fig 10 Kidney; degeneration and necrosis in the epithelial cells of renal tubules at the sub capsular zone ( $\mathrm{H} \& \mathrm{E}, 40_{\mathrm{X}}$.

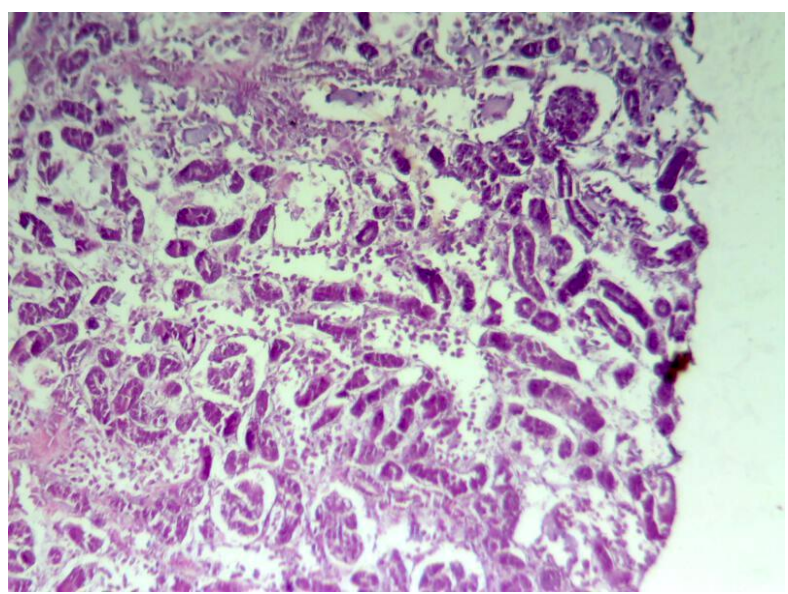

Fig 11 Kidney; vacuolation and necrosis of proximal convoluted tubules. ( $\mathrm{H} \& \mathrm{E}, 4 \mathrm{x})$. 


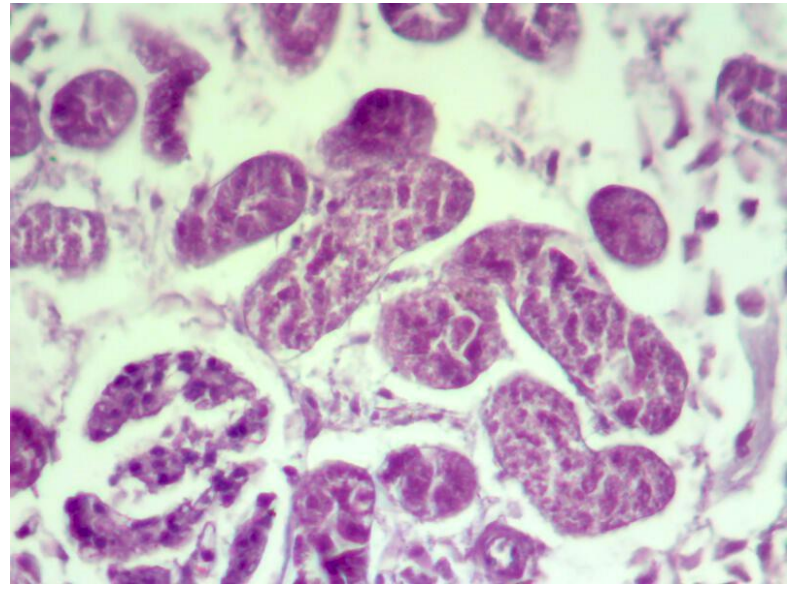

Fig 12 Kidney; vacuolation and necrosis of proximal convoluted tubules (H \& E, 40X).

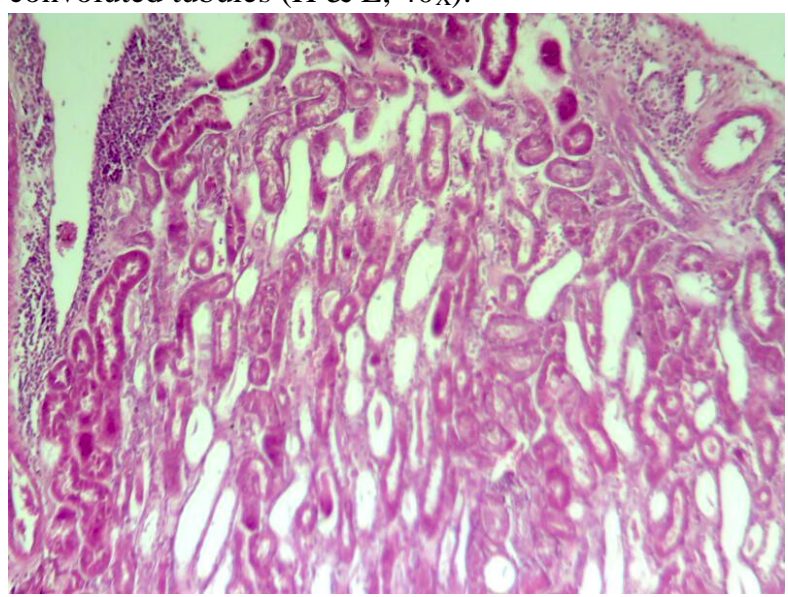

Fig 13 Kidney; dilatation medullary tubules with vascular lumen impacted by haemolysed blood (H \& E, $10 \mathrm{x})$.

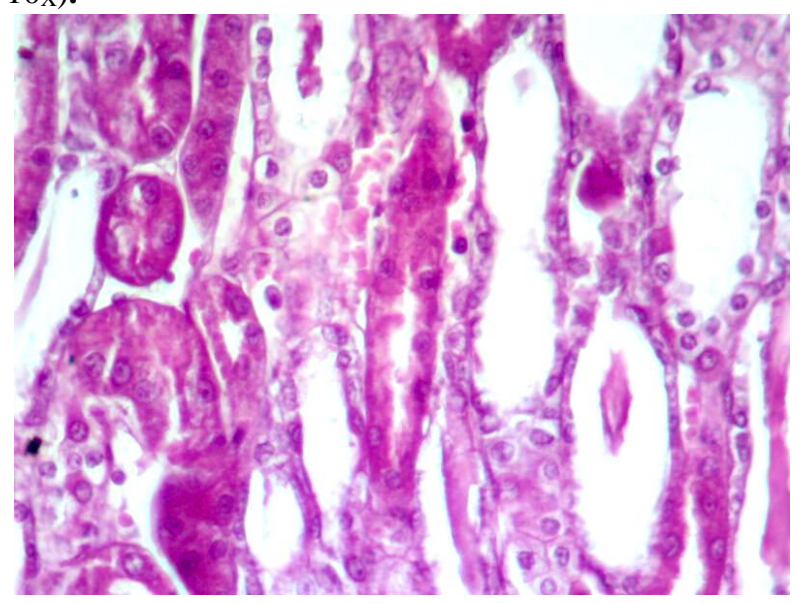

Fig 14 Kidney; dilatation medullary tubules. (H \& E, $40 \mathrm{X})$.

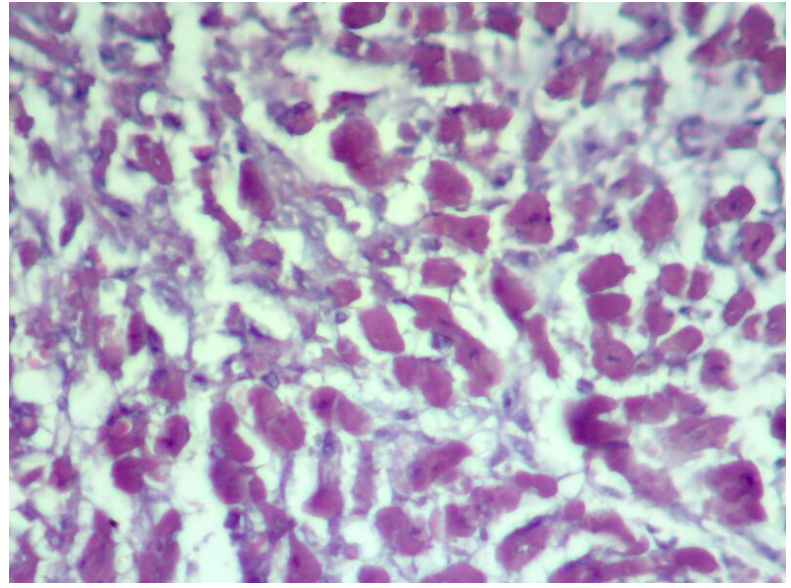

Fig 15 Heart; Clearly vacuolation and congestion of myocardial muscle cells.

$\left(\mathrm{H} \& \mathrm{E}, 40_{\mathrm{X}}\right)$.

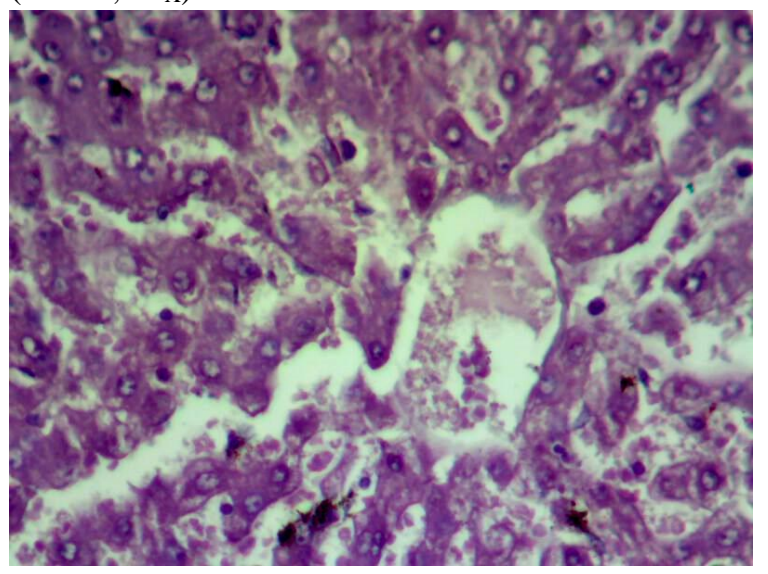

Fig 16 liver; Congested sinusoids with central vein and minimal vacuolation of hepatocytes. (H \& E, 40x).

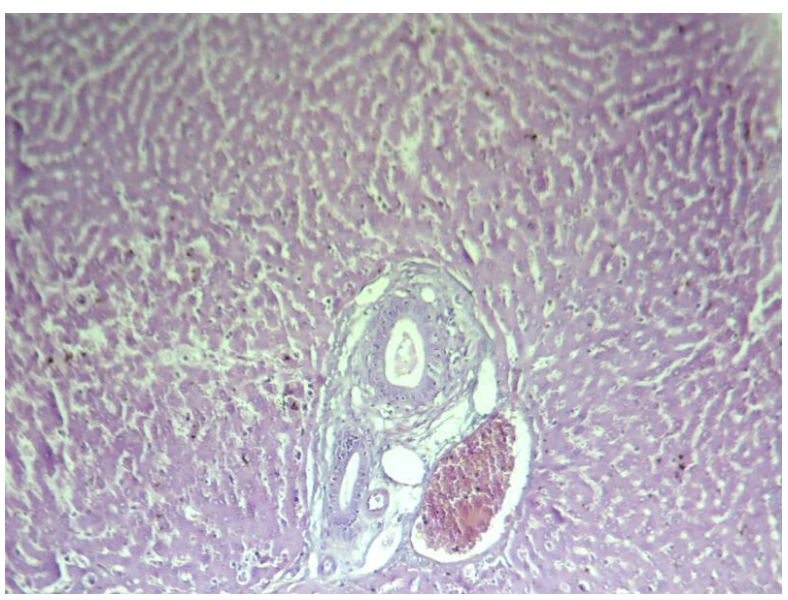

Fig 17 liver; Proliferation of bile duct (H \& E, 10x). 


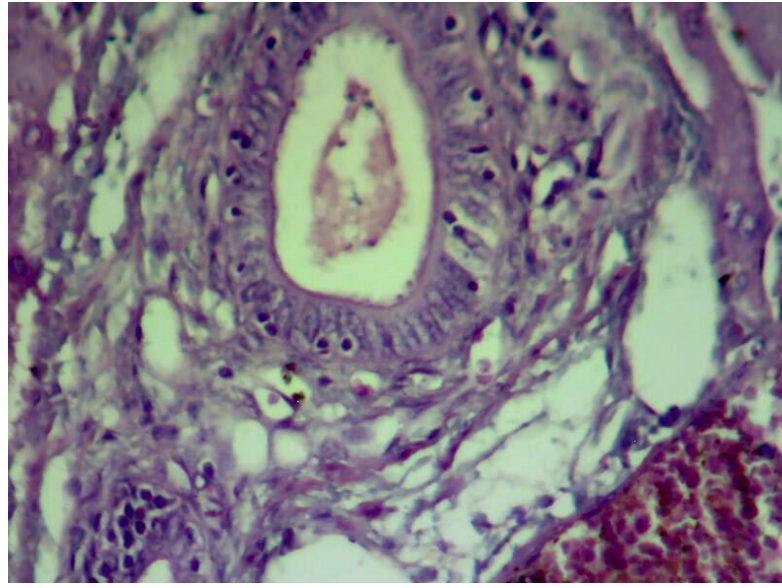

Fig 18 liver; Proliferation of bile duct. (H \& E, 40x).

\section{REFERENCES}

[1] Abdel-Naim, A. B.; Abdel-Wahab, M. H. and Attia, F. F. (1999). Protective effects of vitamin e and probucol against Gentamicin nephrotoxicity in rats." Pharmacol Res., 40 (2). P: 183-187.

[2] Ali, B. H.; Al-Qarawi, A. A.; Haroun, E. M. and Mousa, H. M. (2003). The effect of treatment with gum arabic on gentamicin nephrotoxicity in rats Ren Fail., 25(1). P :15-20.

[3] Baliga, R.; Ueda, N.; Walker, P. D. and Shah, S. V. (1997). Oxidant mechanisms in toxic acute renal failure Am.J.Kidney.Dis. 29. P:465- 477.

[4] Baylis, C.; Renke, H. R. and Brenner, B. M. (1977). Mechanisms of the defect in glomerular ultrafiltration associated with gentamicin administration. Kidney Int;12. P :344-353.

[5] Benjamin, M. M. (1978). Outline of Veterinary Clinical Pathology, 2nd edition. The Iowa University Press, Ames, Iowa, USA.

[6] Bennett, W. M.; Plamp, C. E.; Gilbert, D. N.; Parker, R. A. and Porter, G. A. (1979). Gentamicin nephrotoxicity: dissociation of peak serum levels from renal failure. J. of infect. Dis;140. P :576-580.

[7] Bennett, W. M.; Wood, C. A.; Houghton, D. C. and Gilbert, D. N. (1986). Modification of experimental aminoglycoside nephrotoxicity. American. J. of Kidney Dis. 8. P :292-296.
[8] Brown, S. A.; Newkirk, D. R.; Hunter, R. P.; Smith, G. G. and Sugimoto, K. (1990). Assoc. Offic. Anal. Chem. P: 473- 479.

[9] Carver, A.; Lobell, R.; McCracken, J. S. and Palmer, K. H. (1981). Bovine milk residue depletion of gentamicin following an intramammary infusion of gentamicin sulfate. Research Report A-14453, Sponsor Submitted.

[10] Chilwant, K. S. and Muglikar, A. G. (2012). Effect of honey on gentamicin induced nephrotoxicity in albino rats. International journal of pharmacology and bio science. Vol. 3. P: 458-464.

[11] Cowan, R. H.; Jukkola, A. F. and Arant, B. S. (1980). Pathophysiologic evidence of gentamicin nephrotoxicity in neonatal puppies. Pediatr. Res., 14. P: 1204-1211.

[12] Drury, R. B. and Wallington, E. A. (1976). Carleton's Histological Technique. Oxford University Press, New York, 4th ed. P: 129.

[13] Garetz, S. L. and Schacht, J. (1996). "Ototoxicty of mice and men" In Handbook of auditory research, ed. By R.R. Fay and A.N. Popper, Vol. VII : Clinical aspect of hearing, ed. By T.R. Van De Water, A. N. Popper and R.R. Fay. Springer New York. P: 116-154.

[14] Gobe, G. C. and Axelsen, R. A. (1987). Genesis of renal tubular atrophy in experimental hydronephrosis in the rat. Role of apoptosis. [PubMed] Lab Investig. 56. P :273-282.

[15] Godber, I. M.; Walker, R. D.; Stein, G. E.; Hauptman, J. G. and Derksen, F. J. (1985). Pharmackokinetic, nephrtoxicosis and in vitro antibacterial activity associated with single versus multiple (three times) daily gentamicin treatments in horses. Amer. J. Vet. Res., 56. P: 613-618.

[16] Goto, A. M. (2004). The role of lipid coronary heart disease Kalamazoo, M. I. Upjhion Company.

[17] Heibashy, M. I. and Abdel Moneim, A. E. (1999). Kidney and liver function tests after late Dimethyl sulfoxide (DMSO) administration in rats with gentamicin induced acute renal failure. J. Egypt. Ger. Soc. Zool., 30.(A). P: 35-48.

[18] Heibashy, M. I.; El-Nahla, A. M.; Ibrahim, A. I. and Saleh, Sh. Y. (2009). Comparative study between dimethyl sulfoxide (DMSO),allopurinol and urate oxidase administration in nephrotoxic 
rats induced with gentamicin. 43rd Annual Veterinary Medical Symposium, College of Veterinary Medicine Nursing and Allied Health, Tuskegee University, Alabama, USA.

[20] Heitzman, R. J. (1994). Veterinary Drug Residues. Residues in food producing animals and their products: Reference Materials and Methods. 2nd Edition. Blackwell Scientific Publications, Oxford, U.K. P: Sg 3.6/1 - 3.6/6.

[21] Herscovici, L.; Grise, G.; Thauyin, C.; Lemeland, J. F. and Fillastre, J. P. (1988). Efficacy and safety of once daily versus intermittent dosing of tobramycin in rabbits with acute pyelonephritis. Scandinavian, J. of Inf. Dis; 20. P: 205-212.

[21] Huy, P.; Meulemans, T. B. A.; Wassef, M.; Sterkers, C. and Amiel, C. (1983). Gentamicin persistence in rat endolymph and perilymph after a two-day constant infusion. Antimicrob. Agents Chemother., 23. P: 344-346.

[22] Islam, N. U.; Khan, M. Z.; Saleemi, M. K.; Khan, A.; Bhatti, S. A.; Yousaf, M. and Z.U Hassan, Z. U. (2011). Clinicopathological studies on gentamicin toxicity in White Leghorn commercial layers. Pak. Vet. J., 31. P: 305-308.

[23] Javed, U.; Khan1, M. Z.; Saleemi1, M. K.; Khan1, A.; Javed, I. and Rafique, S. (2013). Toxicopathological Effects of Parenteral Administration of Gentamicin in Growing Broilers. Int. J. Agric. Biol., Vol. 15. No. 3. P: 529-534.

[24] Kavutcu, M.; Canbolat; Ozturk; Vlutepe, O.; Gokhun and Durak. (1996). Reduced enzymatic antioxidant defense mechanisms in kidney tissues from gentamicin treated guinea pigs, Effects of Vit. E and C. Nephron, 72. P : 269-274.

[25] Khan, I.; Khan, M. Z.; Saleemi, M. K.; Javed, I. and Khan, A. (2008). Pathological and biochemical effects of intramuscular gentamicin administration in chicken. Turk. J. Vet. Anim. Sci., 32. P: $345-351$.

[26] Kumar, K. V.; Naidu, M.; Shifow, A. and Ratnakar, K. S. (1999). Probucol protects against of staphylococcus aureus from infected wounds, J. R Soc Med, 92. P : 283-285.

[27] Lamendola, J.; Rock, D. E.; Spreat, S. R. and Pavelchak, J. C. (1980). The bioavailability of gentamicin soluble powder and gentamicin oral solution. Research Report A-13301, Sponsor Submitted.

[28] McMartin, D. N. and Engel, S. G. (1982). Effect of aging on gentamicin nephrotoxicity and pharmacokinetics in rats. Res. Commun. Chem. Pathol. Pharmacol., 38. P: 193-207.

[29] Mingeot-Leclerq, M. P. and Tulkens, P. M. (1999). Aminoglycosides: nephrotoxicity, Antimicrob. Agents Chemother; 43. P: 1003-1012.

[30] Muhammad, D.; Chand, N.; Khan, S.; Sultan, A.; Mushtaq, A. and Rafiullah, (2012). Hepatoprotective role of milk thistle (Silybum marianum) in meat type chicken fed aflatoxin B1 contaminated feed. Pak. Vet. J., 32. P: 443-446.

[31] Nagai, J. (2006). Molecular mechanisms underlying renal accumulation of aminoglycoside antibiotics and mechanism-based approach for developing non nephrotoxic aminoglycoside therapy. Drug Metab Pharmacokinet. 126(5). P: 327-335.

[32] Nagai, J. and Takano, M. (2004). Molecular aspects of renal handling of aminoglycosides and strategies for preventing the nephrotoxicity. Drug Metab Pharmacokinet. 19(3). P: 159-170.

[33] Padmini, M. P. and Kumar, V. J. (2012). A Histopathological Study on Gentamycin Induced Nephrotoxicity in Experimental Albino Rats. IOSR Journal of Dental and Medical Sciences (IOSRJDMS).ISSN: 2279-0861 Volume 1. Issue 1. P: 14-17.

[34] Pavelchak, J. C. and Lamendola, J. F. (1980). Gentamicin kidney residues in bovine following intramuscular and oral treatment. Research Report A-13720, Sponsor Submitted.

[35] Perazella, M. A. (2003). Drug-induced renal failure: update on new medications and uinique mechanisms of nephrotoxicity. Am. J. Med. Sci; 325. P: $349-362$.

[36] Riviere, J. E.; Craigmill, A. L. and Sundlof, S. F. (1991). Handbook of Comparative Pharmacokinetics and Residues of Veterinary Antimicrobials, Chapter six.

[37] Rock, D. E.; Spreat, S. R. and Lamendola, J. F. (1978). Gentamicin piglet injectable - tissue residues following intramuscular injection at three days of age. Research Report A-11972, Sponsor Submitted. 
[38] Saleemi, M. K.; Khan, M. Z.; Khan. A. and Javed, I. (2009). Pathological effects of gentamicin administered intramuscularly to day old broiler chicks. Exp. Toxicol Pathol., 61. P: 425-432.

[39] Shirwaikar, A.; Malini, S. and Kumari, S. C. (2003). Protective effect of Pongamia pinnata flowers against cisplatin and gentamicin induced nephrotoxicity in rats. Indian, J. Exp. Biol. Jan,41(1). P: 58-62.

[40] Sousa, V. B.; Dutra, I. P.; Lucena, H. F.; Medeiros, H. C.; Guerra, G. C.; Junior, R. F.; Araujo, A. A. and Alves, M. F. (2009). Amikacin Induces Renal Morphohistological Alterations in Wistar Rats. Arquivos de medicina , 23(6). P :205-208.

[41] Taha, A. M. (1993). Effect of gentamicin on the histopathology, histochemistry and biochemistry of kidney of albino rats. The New Egypt. J. Med., 8(4). P: 956-961.

[42] Yoshiyama; Kobayashi, T. and Tomonaga, F. (1992). Chronotoxical Study Of Gentamicin Induced Nephrotoxicity In Rats Journal Of Antibiotics May. 